\title{
Capturing the Mainstream: Publisher-Based and Subject-Based Approval Plans in Academic Libraries
}

\author{
Karen A. Schmidt
}

Approval plans in large academic research libraries have had mixed acceptance and success. Much of the negative reaction may be caused by not designing a plan suitable for the book market and the needs of research libraries. The author compares the viability of subject-and publisher-based plans for academic libraries in both domestic and international markets and presents the case for the overriding success of the publisher-based plan for domestic publications and the subject-based plan for international markets. The intrinsic differences between the two types of plans are discussed, and the publishing industries of North America and Europe are reviewed for their impact on approval plans covering various countries. The experience of the University of Illinois-Urbana Library is presented as a specific case for the relative success of both types of plans. The collection, the library organization, and the vagaries of the publishing industries of many countries form the basis for selecting the proper plan which is most economical.

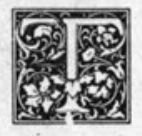

he consensus of the research on approval plans appears to be that approval plans are effective and efficient, but only when certain objective realities are present. These practicalities include having a clearly defined collection development statement; library selectors who understand the collection development policy, agree with it, and are prepared to work together for the mutual benefit of the collection; an approval plan profile which reflects this collection development policy; an adequate aquisitions staff to evaluate the plan properly in view of changing curricula, the plan's return rate, and the collection's needs; and a vendor who can appreciate the idiosyncrasies of each library and can perform according to the library's expectations. The research, unfortunately, in the main part revolves around the question of having or not having an approval plan and around the mechanics of slips and streamers and stamping. The question of types of plans has not been examined in detail, yet there are several factors affecting types of plans which bear examination and are, in fact, of primary importance.

The profile of an approval plan is a coded representation of areas in which the library wishes to collect. It usually consists of key terms and vendor-specific numbering schemes of an intricate nature. The profile is the key to translating a library's approval plan needs to the vendor. It also is the major source of trouble, is timeconsuming for both the vendor and library to create, and is, almost invariably, in a constant state of flux. All the other factors which are commonly thought of as being points of difficulty with approval plans-

Karen A Schmidt is acquisitions librarian at the University of Illinois-Urbana, Illinois 61801. This paper was presented at the ACRL Fourth National Conference in Baltimore, April 9-12, 1986. 
problems such as uneven shipments or inadequate selection-are factors internal to the library or the vendor, and thus, within their individual power to correct. The profile is the only way in which the vendor and library interact and is, therefore, the heart of the subject-based approval plan.

Because of the importance of, and potential for, problems which the subject profile presents, it is useful to look at the various types of approval plans in academic libraries in order to see if some simplification of the subject plan can be made. It is common for academic libraries which accept the notion of approval plans to have at least two different types of plan: a subject-based plan and a university press plan. The latter is, of course, a specialized publisher-based plan. With the subjectbased plan, the library's collection development statement (or some subset thereof) in key-term or coded form is matched with the vendor's subject profile. Readership levels are negotiated, as are costs and the subjects to be included with the vendor. The books which are sent are chosen on the basis of these arrangements, the selectors come to agreements on where titles belong, and the acquisitions department monitors in a continuing manner the results of the agreements reached. No matter how detailed the arrangements are, subject-based plans have inherently a measure of subjectivity in matching subject concepts to individual titles. Conversely, in the university press plan, a list of accepted university presses is agreed upon at the beginning, and the books from these presses are sent. The agreement approaches that of a standing order or blanket order, although it is uncommon for a vendor to reject any returns of nonselected books. Providing the vendor is reliable, and since the basis for selection is utterly objective, little or no monitoring is necessary.

It is illuminating to review what happens to each title under the two types of plan. In a subject-based plan, selection occurs on many levels. The vendor acts as the selector at the first instance and may profile books from publisher's blurbs and reexamine the book once it is in hand. The book is matched to the library's profile, the vendor makes appropriate purchasing agreements with the publisher, and the book is sent to the library. Once in the library, the selection process begins again, with selectors reviewing the book and making selections and negotiations with other librarians. The subject-based plan becomes, in effect, a bookstore in which books are examined and selected or rejected. The subject plan also poses the question of whether a particular title will be sent: "profiling" is a kind of classification process, and the vendor's classification may not match that of the subject selector. If the profiling is at all detailed, the book may be described differently from the way the selector might expect, and thus, may not be sent. Many vendors supply the library with various types of lists of titles expected on approval. Such lists can be checked, although this is a timeconsuming process. Anyway, the lists may not match titles sent. The obvious answer is to send all firm orders to the approval vendor, although this is not usually a wise use of resources, since libraries should use different vendors for different materials, depending upon the vendor's individual strengths.

In university press plans, true selection as an intellectual process occurs only once: when it is agreed that a press will be included in the plan. Selectors are familiar with the products of the university presses and accept that a title published by, say, the University of Chicago Press, will be scholarly and necessary to the academic library collection. Selectors may review the books as they arrive, but rarely do they select (or, more accurately, reject) titles. The vendor is not required to preselect and describe the book, although there are many who do. This type of plan has the added benefit of assuring what will be received, without reviewing vendor lists or selecting vendors on the basis of approval plan agreements.

The nature of the domestic market is such that many publishers seek out what might be perceived as "territories" of publishing, which are well known to informed librarians. As an example, it is accepted that Wiley Scientific will produce scholarly scientific titles which will be of 
interest to academic libraries. It is likely that such libraries will have standing orders for Wiley's various series publications. Similarly, we recognize that Harper and Row will publish worthwhile literary authors and good books of general interest. Because of this generalized knowledge, librarians as selectors feel comfortable with the works of the domestic trade market. It is likely that these books will become part of the library's collection, but a subject-based plan cannot, by its nature, reflect this knowledge. Libraries construct elaborate profiles, ask vendors to determine if each title fits, then begin the selection process again by reassessing each title in the light of their collections.

It is a common configuration within the academic research library to have subject specialists who may be independent subject librarians or bibliographers or may be part of an acquisitions department or other technical service area. These persons usually are well trained in their particular area of expertise to identify and select items from a wide array of material. It is, therefore, a very inefficient use of personnel resources to ask these librarians to become involved in the selection of easily identified and acquired material. Just as it is not good economic or professional sense to ask original catalogers to handle OCLC cataloging, neither is it practical or cost-efficient to request that trained bibliographers identify Harper and Row books. Their knowledge of their subject area is far better spent in identifying fugitive and difficult materials than in dealing with what can easily and reasonably be expected to be an automatic acquisition for an academic library collection.

Conversely, a publisher-based plan provides economies in a number of different ways. First, the books expected are known quantities. Like the university press plans, once a publisher is selected, the selection process is virtually over. There is, therefore, a savings in both selectors' and acquisitions staff's time. There also may be materials budget advantages if vendors are willing to increase discounts for more easily managed approval plans with a high rate of acceptance. Money tied up in continuations budgets for publishers' se- ries may be "freed" to purchase series titles as they appear in monographic form; this may well enable fund managers to handle yearly expenditures more easily.

Publisher-based plans do not ignore subjects but subordinate them to the overall concept. One may request that books on, say, theology be exempted from coverage or be provided as details on "exclusion forms" instead. Of more importance are the readership level and format of the books. One may exclude popular level titles and reprints or expensive editions. The fewer the exclusions, though, the more effective and understandable is the plan.

As described later, the University of Illinois-Urbana Library made the shift from subject- to publisher-based approval plans, following a very simple experiment which is believed to be beneficial to every large academic research library having a subject-based approval plan. Recent annual publisher's catalogs from a few wellknown publishers were chosen and checked against our holdings. It was found that the holdings of these titles were well over 90 percent. In checking to see if these titles had come as a result of our subject-based plan or because of individual firm orders the results were less cheering: a significant portion (and in some subject areas, a majority) of titles came as a result of firm orders. The approval vendor supplied a list of publishers issuing a significant number of titles received as a result of our subject-based approval plans, which was modified somewhat to reflect the specific interests of our library collection. Because of the findings of the study, a change from an unsatisfactory (in terms of titles received and titles rejected) subject-based to publisher-based approval plan was implemented.

The results in terms of the return rate for books, the ability to predict which titles are expected, and the savings in personnel time and energy for both professionals and support staff have been significant, as has been the currency of acquisition of mainstream domestic titles.

Do the same considerations apply when dealing with nondomestic titles? Foreign publishing has a different structure from 
that of America. The same objectives of the collection development policy and the same factors concerning approval plans exist. What is different is the publishing houses, their physical distance from North America, and our own knowledge of the publishing industry in Europe and elsewhere. To develop successful collections representative of these foreign countries, it is extremely important to have current and accurate access to information concerning new publications. While $\mathrm{Pub}$ lishers Weekly and like publications keep selectors informed about North American publishing, there are few European publications which reach us in a timely fashion and allow us to make selections immediately. Additionally, foreign print runs are usually smaller than American, which increases the necessity to purchase quickly. Our knowledge of the publishing houses, too, is lessened not only because of simple geography, but also because the business of publishing in Europe and Asia frequently is carried out in a manner which sometimes mystifies us. For example, it is a common misconception that European publishers and vendors can give North American libraries discounts, but for some inexplicable reason refuse to do so. (AntiAmericanism, perhaps?) In fact, there are no discount schedules to pass along to customers in North America, due to the economics of publishing in many of these countries. Likewise, copyright agreements between European and United States and Canadian publishers are ill understood. It is not uncommon to find selectors "playing the market" by trying to second-guess which Springer or Oxford University Press edition will cost less or be published first. Such misconceptions about the European publishing industry reveal the extent to which we need to rely upon our European and other foreign vendors for their understanding of their own economic and scholarly communities and their ability to translate our needs into their business language. A factor of great importance is the homogeneity of the publishing industry in Europe, western Europe particularly. Publishers tend to deal in one subject area to an even greater extent than is done in the United States. The effect upon the development of a traditional subject-based approval plan is significant.

With all these considerations, the argument against approval plan subject profiles makes less sense than it does with domestic publishers. While all the inherent problems with the subject profiles still apply, regardless of the geographical region, the less information known about a group of publications the more meaningful the role of the vendor in the collection development process. Thus, it is likely that an academic research library will need to depend on a European vendor's subject profile to obtain books quickly, unless that library has a subject specialist so familiar with the publishing market of the country in question that a subject profile for that country is redundant. However, it is important to reiterate that publishing houses in many parts of Europe are focused upon relatively narrow subject ranges and have more homegeneity of readership level than their American counterparts. A subject-based plan for foreign countries, therefore, is not unlike a publisher-based plan for this country.

As a case in point, the University of Illinois-Urbana library has a number of approval plans, both subject- and publisherbased. As described above, the domestic subject-based profiles were replaced by publisher-based profiles because the subject profiles were imperfect representations of the collection development needs of the library and because the selectors did not have sufficient faith in the profile to provide the books they thought appropriate for the collection. The subject-based profile caused very high return (rejection) rates, some of which approached 60 percent; an economically intolerable situation. Now, the publisher-based plan has return rates of less than 10 percent. Additionally, the library has subject-based profiles with several European vendors who are able to interpret the library's needs into specific book selections. In the case of area studies, the library relies on blanket orders, which are not primarily based on subject consideration, but, like publisherbased plans, limit what is sent by broad subject and format categories. Over the 
past few years, following the simple maxim that subject-based profiles are more likely to succeed when less is known about an area's publications has proven to be a successful formula for acquiring the easy-to-identify titles.

It is important for academic libraries to ask not only the why of approval plans but also the what. It is the less obvious management question concerning approval plans and is the more important. Once committed to an approval plan-which should be an accepted and useful component of collection development for academic libraries-it is far more interesting and useful to review exactly what the plan is and can do. Does it duplicate the work and knowledge of the selectors? If the library's selectors are professionals trained in the subject area, it is unlikely a subject plan is needed for domestic publications. What kind of staff will maintain the mechanical points of the plan? If the approval plans take more than 1.0 to 1.5 FTE to maintain, then the plans are too cumbersome. If there is adequate knowledge about the publishers of any one country, then there is little need for a subject-based plan. The approval plan is an adjunct to good selection and economic management of the academic library. It does not replace the need for a collection development statement, nor is it a replacement for the subject specialist, but a useful tool which provides for the greatest use of the professional potential within academic libraries, by freeing selectors from mundane activities and thus enabling them to concentrate on the truly professional aspects of their work. 